OPEN ACCESS

Edited by:

Raffaella Balestrini,

Institute for Sustainable Plant

Protection, National Research Council

(CNR), Italy

Reviewed by:

Franco Faoro,

University of Milan, Italy

Walter Chitarra,

Council for Agricultural and

Economics Research (CREA), Italy

*Correspondence:

Tetyana Nosenko

tetiana.nosenko@

helmholtz-muenchen.de

Robert Hänsch

rhaensch@tu-braunschweig.de

Specialty section:

This article was submitted to

Forest Ecophysiology,

a section of the journal

Frontiers in Forests and Global

Change

Received: 15 January 2021

Accepted: 15 March 2021

Published: 06 April 2021

Citation:

Nosenko T, Hanke-Uhe M, Heine PA,

Shahid A, Dübel S, Rennenberg H, Schumacher J, Winkler JB,

Schnitzler J-P, Hänsch $R$ and Kaufholdt D (2021) Plant Defense Proteins as Potential Markers for Early

Detection of Forest Damage and

Diseases.

Front. For. Glob. Change 4:654032. doi: 10.3389/ffgc.2021.654032

\section{Plant Defense Proteins as Potential Markers for Early Detection of Forest Damage and Diseases}

\author{
Tetyana Nosenko ${ }^{1 *}$, Manuel Hanke-Uhe ${ }^{2}$, Philip Alexander Heine ${ }^{3}$, Afsheen Shahid ${ }^{4}$ \\ Stefan Dübel ${ }^{3}$, Heinz Rennenberg ${ }^{4,5}$, Jörg Schumacher ${ }^{2}$, Jana Barbro Winkler ${ }^{1}$, \\ Jörg-Peter Schnitzler ${ }^{1}$, Robert Hänsch ${ }^{5,6 *}$ and David Kaufholdt ${ }^{6}$
}

${ }^{1}$ Research Unit Environmental Simulation (EUS), Institute for Biochemical Plant Pathology, Helmholtz Zentrum München, Neuherberg, Germany, ${ }^{2}$ Faculty for Forest and Environment, Eberswalde University for Sustainable Development,

Eberswalde, Germany, ${ }^{3}$ Department of Biotechnology, Technische Universität Braunschweig, Braunschweig, Germany, ${ }^{4}$ Institute of Forest Sciences, Chair of Tree Physiology, Albert-Ludwigs-University Freiburg, Freiburg, Germany, ${ }^{5}$ Center of Molecular Ecophysiology (CMEP), College of Resources and Environment, Southwest University, Chongaing, China, ${ }^{6}$ Institute of Plant Biology, Technische Universität Braunschweig, Braunschweig, Germany

Keywords: forest disease diagnostic, molecular markers, antimicrobial peptides, defensins, plant defense

\section{ADDRESSING THE PROBLEM - WHY FORESTRY NEEDS DIAGNOSTIC TOOLS?}

Over the last two decades, European forest ecosystems have been exposed to increasing stress associated with an increasing number, duration and severity of extreme events triggered by climate change (Dyderski et al., 2018). For forest plants, the concomitant stresses are not limited to direct detrimental effects of rising temperatures, drought and heavy rainfall, but also include enhanced virulence of native plant pathogens and herbivores and the introduction of new pests (Stenlid and Oliva, 2016). The detection of forest diseases at an early stage, when visible symptoms cannot yet be observed, is a crucial prerequisite to counteract regional spreading of pathogens. However, the effective monitoring of forest damage and diseases requires reliable and easy-to-use portable test systems.

\section{CURRENT METHODS FOR DETECTION AND DIAGNOSIS OF FOREST DAMAGE AND DISEASES IN AN ASYMPTOMATIC STAGE}

For the detection and asymptomatic diagnosis of plant diseases, currently, a wide variety of biochemical molecular methods is applied. These approaches include well-established methods such as polymerase chain reaction, immunofluorescence, fluorescence in situ hybridization, enzyme immunosorbent assay and flow cytometry, and the use of portable sensors developed on the basis of the above-mentioned laboratory techniques. For a detailed description of the principles, advantages, and disadvantages of these methods we recommend several recently published review articles by Fang and Ramasamy (2015), Lau and Botella (2017), and Luchi et al. (2020). A common feature of most molecular biology techniques is that they are based on the recognition of pathogen DNA, RNA, or protein molecules present in the sampled plant tissue and often assume an advanced stage of the infection, which has spread over a large part of the tree. Such molecular markers are often highly specific for a particular pathogen and are therefore susceptible to false negative results in diseases caused by non-indigenous pathogens (i.e., invasive species) or species with high genetic diversity (Luchi et al., 2020). Therefore, other types of molecular markers are required for the detection of disease by different types of stress in forest populations at the early, asymptomatic stage. 
Several advanced techniques have been applied to monitor stress conditions in agricultural land and forests, including biophysical methods such as thermographic, hyperspectral reflectance, and advanced fluorescence imaging techniques, as well as metabolome analyses such as profiling of volatile organic compounds or plant hormones (Martinelli et al., 2015). However, the interpretation of the results obtained with these methods depends on the availability of large amounts of data that would allow to distinguish between normal seasonal and diurnal variations of the measured parameters and their pathological profiles, and on appropriate data processing and analytical techniques. Both data collection and data analysis require special experience and are not field applicable.

To overcome these disadvantages, the development of a new test system based on host immune responses could be a promising strategy. We hypothesize that new host-derived markers, in combination with serological techniques already well-established for forest disease diagnosis, will provide a promising tool for the detection of forest damage and diseases at their early asymptomatic stage. Such a prospective technology will be an antibody-based Lateral-Flow-Test (LFT) targeting a particular stress-induced plant defense protein (Figure 1A).

\section{PREREQUISITES OF GENE- OR PROTEIN-BIOMARKERS FOR THE EARLY DETECTION OF DISEASES}

First of all, we have to keep in mind that the purpose of such markers is not to detect a particular species of plant pathogens or herbivores but rather to identify a general problem resulted from a predefined range of causative agents. Therefore, good hostderived markers should respond to a broad spectrum of stressors. In addition to the broad target range, potential markers are expected to exhibit specific spatio-temporal expression pattern. Disease-causing agents trigger two types of reactions in plants: a local reaction restricted to the attacked tissue and systemic reactions including biochemical and biophysical changes in tissues and organs distal to the affected locus (Eyles et al., 2010). Only genes or proteins involved in systemic reactions constitute potential markers for the early disease detection. Finally, in order to have an unrestricted time for sampling, a reliable marker should be rapidly upregulated and maintain a high expression level during a particular stress with negligible diurnal variation.

\section{ANTIMICROBIAL PEPTIDES AS POTENTIAL MARKERS FOR THE EARLY DETECTION OF FOREST DISEASES}

Are there any proteins in plants that fulfill the above criteria? To answer this question, we present here the relevant current knowledge about a large group of proteins of innate plant immunity, the antimicrobial peptides (AMPs), with special emphasis on the defensins as the best-studied class of AMPs. These peptides comprise a diverse group of short, cysteinerich proteins, some of which are also known as PathogenesisRelated (PR) proteins. AMPs, which are ubiquitous in higher plants, are characterized by a remarkable primary sequence variation and high stability of their three-dimensional protein structure maintained by disulfide bonds formed by highly conserved cysteine residues (Campos et al., 2018; Kovaleva et al., 2020). Based on their tertiary structure, AMPs are classified into defensins, thionins, lipid-transfer proteins, heveins, and other multigene families. Depending on the species, each family consists of dozens to hundreds of genes. AMPs are secreted mainly in the apoplastic space of peripheral cell layers and act as the plant's first line of defense against pathogenic fungi, bacteria, viruses, and herbivores (Lazzaro et al., 2020).

\section{Spectra of the AMP Antimicrobial Activities}

The majority of AMPs are positively charged at their surface and cause broad-spectrum antimicrobial activity by interacting with negatively charged microbial membranes. This interaction leads to a change in membrane structure, followed by cell death or, in some cases, to an intrusion of AMPs into the pathogen interior, where they interact with specific intracellular targets (van der Weerden et al., 2008). Other known AMP mechanisms of function include interaction of AMPs with specific lipid, protein, or oligosaccharide molecules of bacterial or fungal cell walls (Thevissen et al., 2000), inhibition of fungal phytopathogenic proteins (Slavokhotova et al., 2014), induction of systemic iron deficiency (Hsiao et al., 2017), and inhibition of digestive enzymes of insects (Major and Constabel, 2008). Each particular mechanism determines the spectrum of antimicrobial activities and spatiotemporal expression patterns of individual AMPs.

The specificity of antimicrobial activity and target range of individual AMPs vary widely within and between species. The type I defensins AtPDF1.1 and AtPDF1.2 from Arabidopsis thaliana are probably the best studied AMPs involved in nonspecific plant resistance to a wide range of biotic and abiotic challenges such as necrotrophic fungi, bacteria, herbivorous insects, and an excess of heavy metals (Nguyen et al., 2014; Hsiao et al., 2017). Many AMPs are known to possess a more specific antimicrobial activity with their target range limited to a particular taxonomical group of plant pathogens. These limitations are due to the aforementioned ability of some AMPs to attach to membrane or cell wall molecules specific to certain groups of microorganisms such as fungi-specific sphingolipids or digestive enzymes of insects (Thevissen et al., 2000; Wijaya et al., 2000; Medeiros and Pockman, 2011). The most striking example of extreme functional specialization are defensin-like peptides involved in the regulation of plant-bacterial symbiosis. These AMPs are able to differentiate even between different strains of a symbiotic bacterium (Simsek et al., 2013).

\section{Spatio-Temporal Patterns of Antimicrobial Peptide Formation Under Stress}

Similar to their target ranges, plant AMPs show a great heterogeneity in tissue specificity and longevity after onset of the stress response. Many functionally promiscuous AMPs are known to be tightly integrated into general immune signaling networks and therefore form an integral part of the plant's systemic response to infection or environmental stress. For example, the aforementioned broad-spectrum defensins 


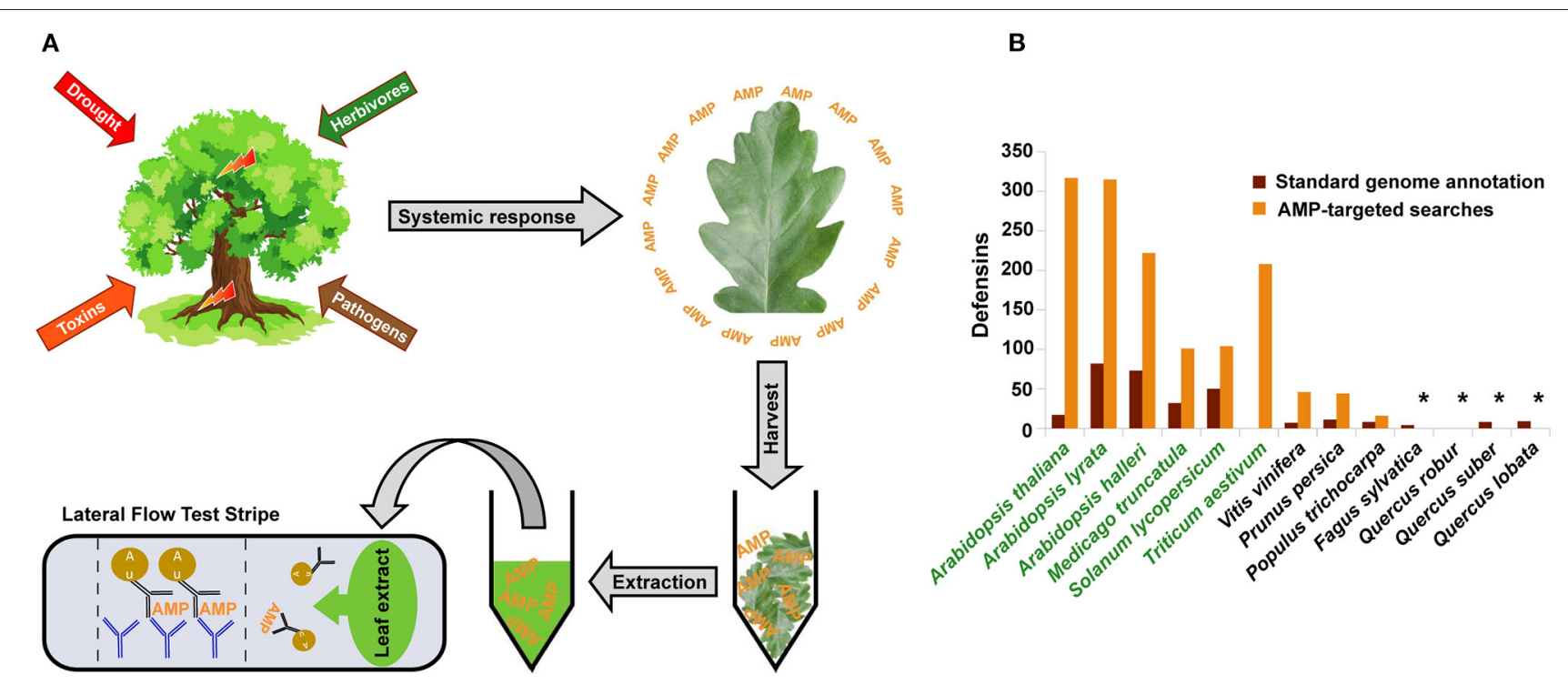

FIGURE 1 | Plant defense proteins as potential markers for an early detection of forest diseases. (A) Schematic representation of a plant proteins-based test system. In trees, visible symptoms often appear years after disease induction. At molecular level, plants develop a systemic defense response from hours to days after onset of infection or stress. Plant defense proteins, such as antimicrobial peptides (AMP), can be detected in leaf extracts using Lateral-Flow-Test (LFT) with two specific antibodies. The first anti-AMP antibody forms a mobile complex with an AMP molecule and flows in the direction of the stripe region containing an immobilized second anti-AMP antibody capturing this complex. If AMPs are present, the color of the corresponding stripe region changes because of macroscopic gold particles bound to the mobile anti-AMP antibody. Using LFTs, tree diseases can be detected at an early asymptomatic stage. In addition, more detailed results are conceivable with a multiple-readout test stripe containing multiple test lines with two antibody pairs against different antigens, e.g., one antibody pair against a general stress-marker and another against an AMP characterized by a narrow spectrum of antimicrobial activity. More technical details of LFTs are described elsewhere (Yetisen et al., 2013). (B) Current state of knowledge on defense proteins in woody plants: The case of defensins. Total number of defensin and defensin-like genes predicted using standard homology-based genome annotation (brown) and AMP-targeted (orange) pipelines are given for selected herbaceous and woody plant species (species names in green and black, respectively). Information about the number of genes identified using the AMP-specific approaches is available for $A$. thaliana, $A$. halleri, and $A$. lyrata (Silverstein et al., 2005), M. truncatula (de Bang et al., 2017), T. aestivum (International Wheat Genome Sequencing, 2018), V. vinifera (Giacomelli et al., 2012), S. lycopersicum, P. persica, and P. trichocarpa (Liu et al., 2017). Stars indicate species, for which corresponding information is not available.

AtPDF1.1 and AtPDF1.2 are known to be part of the plant's immune response triggered by the phytohormones ethylene and jasmonic acid. In response to infestation with necrotrophic fungi and bacteria, these AMPs are upregulated both locally at the inoculation site and systemically in tissues distal to the infection site as early as $6 \mathrm{~h}$ after the infection and remain detectable during at least the following 3 days (Hsiao et al., 2017). A broad-spectrum defensin PtDef from Populus trichocarpa showed a graduate increase of its expression levels in response to abiotic stresses, such as drought and cold, during seven days of the experiment (Wei et al., 2020). Further examples of systemic AMPs involved in either hormone-mediated or reactive oxygen species-activated MAPK signaling cascades are described in the review by Bolouri Moghaddam et al. (2016). In contrast, defensin-like nodular peptides exhibit a very high tissue specificity: they are not only expressed exclusively in root nodules, but also differentiate between several nodular zones (Roux et al., 2014); their temporal expression patterns are finetuned to the developmental stages of bacterial symbionts (Marx et al., 2016).

Some of the examples presented above suggest that AMP markers are applicable for the early detection of plant diseases. Depending on the task, the test-system may utilize either general-stress response, or more specific (e.g., fungal infection)
AMP markers, or both (i.e., a dual-readout LFT; Gong et al., 2018). However, along with advantages, we have to consider challenges for developing a test-system for the early detection of plant diseases.

\section{How Much Do We Know About AMPs in Perennial Woody Plants?}

Currently, the greatest obstacle to the selection of host-derived markers for early detection of forest diseases is our limited knowledge on defense mechanisms in trees. The plant immune system has been studied primarily in the model organism Arabidopsis and several important crop species. These studies show an incredible between-species variation of gene copy number and biological functions of plant defense proteins, even between closely related species (Hanks et al., 2005; MondragonPalomino et al., 2017). Because of this variation, it is impossible to extrapolate findings derived from short-lived herbaceous plants directly to long-lived woody plants. As they are at the forefront of the host-parasite arms race, defense genes are subject to rapid diversification, which hinders their identification using homology-based techniques (Liu et al., 2017). To overcome such obstacles, specific computational approaches have been developed for the identification of genes involved in plant 
defense. In the case of AMPs, gene identification methods are based on the conserved patterns of cysteine residues and presence of N-terminal signal peptides. In Figure 1B, we show that the number of genes annotated in plant genomes as AMPs varies considerably depending on the identification method applied. So far only very few genomes of perennial woody plants have been screened using specific AMP-targeting approaches. In addition, only very few studies have addressed the functions of AMPs in trees [e.g., Pinus sylvestris (Hrunyk et al., 2017; Khairutdinov et al., 2017), Picea glauca (Picart et al., 2012), and P. trichocarpa (Major and Constabel, 2008; Wei et al., 2020)]. Nevertheless, the results of these studies support the following statements: (a) There is a high diversity of AMPs in long-living woody plants. (b) Similar to herbaceous species, AMPs in tree species are involved in the development of resistance to a variety of biotic and abiotic stresses. (c) The target range and mechanisms of antimicrobial activity of individual AMPs of woody plants are species-specific.

\section{CONCLUDING REMARKS}

Defensins and other AMPs are promising candidates for early detection of plant diseases independent of a stress-factor in general. An AMP-dependent test-system can be designed for the tree species dominant in particular regions and used as a part of the regional forest monitoring program. Engineering highly specific antibodies is challenging but possible with modern techniques for the monoclonal antibody production like phage display (Bradbury et al., 2011). Unfortunately, the knowledge on

\section{REFERENCES}

Bolouri Moghaddam, M. R., Vilcinskas, A., and Rahnamaeian, M. (2016). Cooperative interaction of antimicrobial peptides with the interrelated immune pathways in plants. Mol. Plant Pathol. 17, 464-471. doi: 10.1111/mpp.12299

Bradbury, A., Sidhu, S., Dübel, S., and McCafferty, J. (2011). Beyond natural antibodies: the power of in vitro display technologies. Nat. Biotechnol. 29, 245-254. doi: 10.1038/nbt.1791

Campos, M. L., Liao, L. M., Alves, E. S. F., Migliolo, L., Dias, S. C., and Franco, O. L. (2018). A structural perspective of plant antimicrobial peptides. Biochem. J. 475, 3359-3375. doi: 10.1042/BCJ20180213

de Bang, T. C., Lundquist, P. K., Dai, X., Boschiero, C., Zhuang, Z., Pant, P., et al. (2017). Genome-wide identification of Medicago peptides involved in macronutrient responses and nodulation. Plant Physiol. 175, 1669-1689. doi: 10.1104/pp.17.01096

Dyderski, M. K., Paz, S., Frelich, L. E., and Jagodzinski, A. M. (2018). How much does climate change threaten European forest tree species distributions? Glob. Chang. Biol. 24, 1150-1163. doi: 10.1111/gcb.13925

Eyles, A., Bonello, P., Ganley, R., and Mohammed, C. (2010). Induced resistance to pests and pathogens in trees. New Phytol. 185, 893-908. doi: 10.1111/j.1469-8137.2009.03127.x

Fang, Y., and Ramasamy, R. P. (2015). Current and prospective methods for plant disease detection. Biosensors 5, 537-561. doi: 10.3390/bios5030537

Giacomelli, L., Nanni, V., Lenzi, L., Zhuang, J., Dalla Serra, M., Banfield, M. J., et al. (2012). Identification and characterization of the defensinlike gene family of grapevine. Mol. Plant Microbe Interact. 25, 1118-1131. doi: 10.1094/MPMI-12-11-0323

Gong, X., Zhang, B., Piao, J., Zhao, Q., Gao, W., Peng, W., et al. (2018). High sensitive and multiple detection of acute myocardial infarction biomarkers based on a dual-readout immunochromatography test strip. Nanomed. Nanotechnol. Biol. Med. 14, 1257-1266. doi: 10.1016/j.nano.2018.02.013 immune responses in woody plants is rudimentary and needs further investigations. Advances in DNA and RNA sequencing technologies make it possible to generate whole genome and transcriptome sequence data for ecologically important forest tree species such as English oak and beech (Mishra et al., 2018; Plomion et al., 2018). This increasing availability of data can partially compensate for the lack of experimental evidence on the diversity, expression type, and tissue specificity of defense proteins of woody plants, information that can be used for the pre-selection of protein markers for developing an antibody-based LFT stripe for early detection of diseases in these species.

\section{AUTHOR CONTRIBUTIONS}

RH, HR, JS, and J-PS conceived the work. TN, DK, RH, and J-PS wrote the manuscript. MH-U, PH, AS, SD, and JW participated in discussions and made intellectual contribution to the manuscript. All authors commented on the manuscript and approved it for publication.

\section{FUNDING}

This work has been supported by a grant (WKF-WF0422WB41300/1-4) from the German Federal Ministry of Food and Agriculture (BMEL) and Federal Ministry for the Environment, Nature Conservation and Nuclear Safety (BMU) in the frame or the Waldklimafonds Program.
Hanks, J. N., Snyder, A. K., Graham, M. A., Shah, R. K., Blaylock, L. A., Harrison, M. J., et al. (2005). Defensin gene family in Medicago truncatula: structure, expression and induction by signal molecules. Plant Mol. Biol. 58, 385-399. doi: 10.1007/s11103-005-5567-7

Hrunyk, N., Gout, R., and Kovaleva, V. (2017). Regulation of gene expression for defensins and lipid transfer protein in Scots pine seedlings by necrotrophic pathogen Alternaria alternata (Fr.). Folia For. Pol. 59, 152-158. doi: 10.1515/ffp-2017-0015

Hsiao, P. Y., Cheng, C. P., Koh, K. W., and Chan, M. T. (2017). The Arabidopsis defensin gene, AtPDF1.1, mediates defence against Pectobacterium carotovorum subsp. carotovorum via an iron-withholding defence system. Sci Rep. 7:9175. doi: 10.1038/s41598-017-08497-7

International Wheat Genome Sequencing (2018). Shifting the limits in wheat research and breeding using a fully annotated reference genome. Science 361:eaar7191. doi: 10.1126/science.aar7191

Khairutdinov, B. I., Ermakova, E. A., Yusypovych, Y. M., Bessolicina, E. K., Tarasova, N. B., Toporkova, Y. Y., et al. (2017). NMR structure, conformational dynamics, and biological activity of PsDef1 defensin from Pinus sylvestris. Biochim. Biophys. Acta Proteins Proteom 1865, 1085-1094. doi: 10.1016/j.bbapap.2017.05.012

Kovaleva, V., Bukhteeva, I., Kit, O. Y., and Nesmelova, I. V. (2020). Plant defensins from a structural perspective. Int. J. Mol. Sci. 21:5307. doi: 10.3390/ijms21155307

Lau, H. Y., and Botella, J. R. (2017). Advanced DNA-based point-of-care diagnostic methods for plant diseases detection. Front. Plant Sci. 8:2016. doi: 10.3389/fpls.2017.02016

Lazzaro, B. P., Zasloff, M., and Rolff, J. (2020). Antimicrobial peptides: application informed by evolution. Science 368:aau5480. doi: 10.1126/science.aau5480

Liu, X., Zhang, H., Jiao, H., Li, L., Qiao, X., Fabrice, M. R., et al. (2017). Expansion and evolutionary patterns of cysteine-rich peptides in plants. BMC Genomics 18:610. doi: 10.1186/s12864-017-3948-3 
Luchi, N., Ioos, R., and Santini, A. (2020). Fast and reliable molecular methods to detect fungal pathogens in woody plants. Appl. Microbiol. Biotechnol. 104, 2453-2468. doi: 10.1007/s00253-020-10395-4

Major, I. T., and Constabel, C. P. (2008). Functional analysis of the Kunitz trypsin inhibitor family in poplar reveals biochemical diversity and multiplicity in defense against herbivores. Plant Physiol. 146, 888-903. doi: $10.1104 /$ pp.107.106229

Martinelli, F., Scalenghe, R., Davino, S., Panno, S., Scuderi, G., Ruisi, P., et al. (2015). Advanced methods of plant disease detection. A review. Agron. Sustain. Dev. 35, 1-25. doi: 10.1007/s13593-014-0246-1

Marx, H., Minogue, C. E., Jayaraman, D., Richards, A. L., Kwiecien, N. W., Siahpirani, A. F., et al. (2016). A proteomic atlas of the legume Medicago truncatula and its nitrogen-fixing endosymbiont Sinorhizobium meliloti. Nat. Biotechnol. 34, 1198-1205. doi: 10.1038/nbt.3681

Medeiros, J. S., and Pockman, W. T. (2011). Drought increases freezing tolerance of both leaves and xylem of Larrea tridentata. Plant Cell Environ. 34, 43-51. doi: 10.1111/j.1365-3040.2010.02224.x

Mishra, B., Gupta, D. K., Pfenninger, M., Hickler, T., Langer, E., and Nam, B. (2018). A reference genome of the European beech (Fagus sylvatica L.). Gigascience 7:giy063. doi: 10.1093/gigascience/giy063

Mondragon-Palomino, M., John-Arputharaj, A., Pallmann, M., and Dresselhaus, T. (2017). Similarities between reproductive and immune pistil transcriptomes of Arabidopsis species. Plant Physiol. 174, 1559-1575. doi: 10.1104/pp.17.00390

Nguyen, N. N., Ranwez, V., Vile, D., Soulie, M. C., Dellagi, A., Expert, D., et al. (2014). Evolutionary tinkering of the expression of PDF1s suggests their joint effect on zinc tolerance and the response to pathogen attack. Front. Plant Sci. 5:70. doi: 10.3389/fpls.2014.00070

Picart, P., Pirttila, A. M., Raventos, D., Kristensen, H. H., and Sahl, H. G. (2012). Identification of defensin-encoding genes of Picea glauca: characterization of PgD5, a conserved spruce defensin with strong antifungal activity. BMC Plant Biol. 12:180. doi: 10.1186/1471-2229-12-180

Plomion, C., Aury, J. M., Amselem, J., Leroy, T., Murat, F., Duplessis, S., et al. (2018). Oak genome reveals facets of long lifespan. Nat Plants 4, 440-452. doi: 10.1038/s41477-018-0172-3

Roux, B., Rodde, N., Jardinaud, M. F., Timmers, T., Sauviac, L., Cottret, L., et al. (2014). An integrated analysis of plant and bacterial gene expression in symbiotic root nodules using laser-capture microdissection coupled to RNA sequencing. Plant J. 77, 817-837. doi: 10.1111/tpj.12442

Silverstein, K. A., Graham, M. A., Paape, T. D., and Vandenbosch, K. A. (2005). Genome organization of more than 300 defensin-like genes in Arabidopsis. Plant Physiol. 138, 600-610. doi: 10.1104/pp.105.060079

Simsek, S., Wood, K., and Reuhs, B. L. (2013). Structural analysis of succinoglycan oligosaccharides from Sinorhizobium meliloti strains with different host compatibility phenotypes. J. Bacteriol. 195, 2032-2038. doi: 10.1128/JB.00009-13

Slavokhotova, A. A., Naumann, T. A., Price, N. P., Rogozhin, E. A., Andreev, Y. A., Vassilevski, A. A., et al. (2014). Novel mode of action of plant defense peptides hevein-like antimicrobial peptides from wheat inhibit fungal metalloproteases. FEBS J. 281, 4754-4764. doi: 10.1111/febs.13015

Stenlid, J., and Oliva, J. (2016). Phenotypic interactions between tree hosts and invasive forest pathogens in the light of globalization and climate change. Philos. Trans. R. Soc. Lond. B Biol. Sci. 371:455. doi: 10.1098/rstb.2015.0455

Thevissen, K., Cammue, B. P., Lemaire, K., Winderickx, J., Dickson, R. C., Lester, R. L., et al. (2000). A gene encoding a sphingolipid biosynthesis enzyme determines the sensitivity of Saccharomyces cerevisiae to an antifungal plant defensin from dahlia (Dahlia merckii). Proc. Natl. Acad. Sci. U.S.A. 97, 9531-9536. doi: 10.1073/pnas.160077797

van der Weerden, N. L., Lay, F. T., and Anderson, M. A. (2008). The plant defensin, $\mathrm{NaD1}$, enters the cytoplasm of Fusarium oxysporum hyphae. J. Biol. Chem. 283, 14445-14452. doi: 10.1074/jbc.M709867200

Wei, H., Movahedi, A., Xu, C., Sun, W., Wang, P., Li, D., et al. (2020). Characterization, expression profiling, and functional analysis of PtDef, a defensin-encoding gene from Populus trichocarpa. Front. Microbiol. 11:106. doi: $10.3389 /$ fmicb. 2020.00106

Wijaya, R., Neumann, G. M., Condron, R., Hughes, A. B., and Polya, G. M. (2000). Defense proteins from seed of Cassia fistula include a lipid transfer protein homologue and a protease inhibitory plant defensin. Plant Sci. 159, 243-255. doi: 10.1016/S0168-9452(00)00348-4

Yetisen, A. K., Akram, M. S., and Lowe, C. R. (2013). Paper-based microfluidic point-of-care diagnostic devices. Lab Chip 13, 2210-2251. doi: $10.1039 / \mathrm{c} 3 \mathrm{lc} 50169 \mathrm{~h}$

Conflict of Interest: The authors declare that the research was conducted in the absence of any commercial or financial relationships that could be construed as a potential conflict of interest.

The handling editor RB declared a past co-authorship with one of the authors J-PS.

Copyright (c) 2021 Nosenko, Hanke-Uhe, Heine, Shahid, Dübel, Rennenberg, Schumacher, Winkler, Schnitzler, Hänsch and Kaufholdt. This is an open-access article distributed under the terms of the Creative Commons Attribution License (CC $B Y)$. The use, distribution or reproduction in other forums is permitted, provided the original author(s) and the copyright owner(s) are credited and that the original publication in this journal is cited, in accordance with accepted academic practice. No use, distribution or reproduction is permitted which does not comply with these terms. 